\title{
Simvastatin protects auditory hair cells from gentamicin-induced toxicity and activates Akt signaling in vitro
}

Yves Brand ${ }^{1,2,4}$, Cristian Setz ${ }^{1,2}$, Soledad Levano ${ }^{1,2}$, Alwin Listyo ${ }^{1,2}$, Eduardo Chavez ${ }^{4}$, Kwang Pak ${ }^{3}$, Michael Sung ${ }^{4}$, Vesna Radojevic ${ }^{1,2}$, Allen F Ryan ${ }^{3,4,5+}$ and Daniel Bodmer ${ }^{1,2^{*}+}$

\begin{abstract}
Background: Inhibitors of 3-hydroxy-3-methylglutaryl-coenzyme A reductase, known as statins, are commonly used as cholesterol-lowering drugs. During the past decade, evidence has emerged that statins also have neuroprotective effects. Research in the retina has shown that simvastatin, a commonly used statin, increases Akt phosphorylation in vivo, indicating that the PI3K/Akt pathway contributes to the protective effects achieved. While research about neuroprotective effects have been conducted in several systems, the effects of statins on the inner ear are largely unknown.

Results: We evaluated whether the 3-hydroxy-3-methylglutaryl-coenzyme A reductase is present within the rat cochlea and whether simvastatin is able to protect auditory hair cells from gentamicin-induced apoptotic cell death in a in vitro mouse model. Furthermore, we evaluated whether simvastatin increases Akt phosphorylation in the organ of Corti. We detected 3-hydroxy-3-methylglutaryl-coenzyme A reductase mRNA in organ of Corti, spiral ganglion, and stria vascularis by reverse transcriptase-polymerase chain reaction (RT-PCR). Moreover, we observed a dose-dependent and significant reduction of hair cell loss in organs of Corti treated with simvastatin in addition to gentamicin, as compared to samples treated with gentamicin alone. The protective effect of simvastatin was reversed by addition of mevalonate, a downstream metabolite blocked by simvastatin, demonstrating the specificity of protection. Finally, Western blotting showed an increase in organ of Corti Akt phosphorylation after simvastatin treatment in vitro.
\end{abstract}

Conclusion: These results suggest a neuroprotective effect of statins in the inner ear, mediated by reduced 3hydroxy-3-methylglutaryl-coenzyme A reductase metabolism and Akt activation.

\section{Background}

Until recently, sensorineural hearing loss due to damage to cochlear hair cells $(\mathrm{HC})$ has been regarded as an inevitable consequence of age, genetic conditions or exposure to certain environmental stimuli. During the past several years, some of the critical intracellular events that mediate damage to HCs have been discovered, using aminoglycoside-induced HC death in vitro as a model [1-4]. It has been demonstrated that small GTPases, such as Ras and $\mathrm{Rho} / \mathrm{Rac} / \mathrm{Cdc} 42$, as well as the c-Jun-N-terminal

\footnotetext{
* Correspondence: dbodmer@uhbs.ch

+ Contributed equally

'Department of Biomedicine, University Hospital Basel, Hebelstrasse 20, 4031

Basel, Switzerland

Full list of author information is available at the end of the article
}

kinase signalling pathway, are activated in cells exposed to the drug and that phoshatidylinositol-3-kinase (PI3K) signalling mediates $\mathrm{HC}$ survival and opposes gentamicin toxicity via its downstream target, the protein kinase AKT [5-9]. After prolonged aminoglycoside exposure, caspases are activated and HCs undergo apoptotic cell death $[10,11]$.

Inhibitors of 3-hydroxy-3-methylglutaryl-coenzyme A (HMG-CoA) reductase, otherwise known as statins, are commonly used as cholesterol-lowering drugs. Statins reduce the incidence of primary and secondary coronary heart disease in clinic trials and act by blocking the enzyme necessary for the production of L-mevalonate, an intermediary product in the synthesis of cholesterol $[12,13]$. During the past decade, evidence has emerged 
that statins also have neuroprotective effects. Animal models suggest that statins may be beneficial in the treatment of multiple sclerosis and during acute stroke [14-20]. Several in vitro and in vivo studies provided evidence that statins activate the protein kinase $\mathrm{B}(\mathrm{PKB} /$ Akt) pathway [21,22]. Work done in the retina has shown that simvastatin, a commonly used statin, increases Akt phosphorylation in vivo, indicating that the PI3K/Akt pathway contributes to central nervous system protective effects achieved [23].

In the inner ear, Cai et al. found that simvastatin protected the hearing of mice deficient in apolipoprotein $\mathrm{E}$ that were fed a high fat diet [24]. However, they attributed this effect to control of hyperlipedemia. Syka et al. demonstrated that atrovastin slows down the deterioration of inner ear function with age in mice. They suggested that atrovastin reduces endothelial inflammatory effects that influence the blood supply to the inner ear [25]. While no experiments were performed, Borghi et al. hypothesized that statins might be useful as a treatment for sensorineural hearing loss due to their metabolic and hemodynamic effects [26]. However, a prospective, randomized, double-blinded clinical trial by Olzowy et al. did not show an effect of atrovastin on progression of sensorineural hearing loss in the elderly [27]. In contrast, Chiu et al. reported that simvastatin exposure produced damage to lateral line HCs in the zebrafish, although the mechanism was not identified [28].

Given these conflicting data, we determine whether or not HMG-CoA reductase is present within the rat cochlea, and whether simvastatin is able to protect mammalian auditory $\mathrm{HCs}$ from gentamicin-induced $\mathrm{HC}$ death. Given the results of Chiu et al. we also evaluated simvastatin for $\mathrm{HC}$ toxicity [28]. In addition we investigated the metabolic pathway involved in simvastatin effects, and whether this drug increases Akt phorphorylation in the organ of Corti (OC).

\section{Results}

HMG-CoA reductase mRNA is expressed in the cochlea

HMG-CoA mRNA were detected in the OC, spiral ganglion (SG), and stria vascularis (SV) using specific primer sets (Table 1 ). The amplification of $\beta$-actin confirmed a successful synthesis of cDNA. The specificity of the designed primers was confirmed using cDNA from rat brain tissue. One single band of the correct size for every tissue was observed (Figure 1). Omission of cDNA in the PCR mixture served as negative control.

\section{Simvastatin has no toxic effect on HCs and protects HCs from gentamicin-induced $\mathrm{HC}$ damage in vitro}

To exclude a toxic effect of simvastatin, the OCs were cultured with the highest dosages used in this study $(100 \mu \mathrm{M})$ for 72 hours. The number of HCs was compared between cultured OCs in presence and absence of simvastatin. Because no difference was found, a toxic effect of simvastatin was excluded. Untreated control OCs and those treated with simvastatin showed three orderly rows of outer hair cells $(\mathrm{OHCs})$ and a single row of inner hair cells (IHCs) (Figure 2).

As expected, gentamicin treatment led to a loss of HCs (Figure 2). Treatment with both gentamicin and simvastatin at the concentration of $1 \mu \mathrm{M}$ significantly increased $\mathrm{OHC}$ survival in the middle and basal cochlear turn (Figure 3). Whereas treatment with both gentamicin and simvastatin at the concentration of 10 $\mu \mathrm{M}$ and $100 \mu \mathrm{M}$, resulted in increased $\mathrm{OHC}$ survival in all cochlear turns (Figure 3 ). The protective effect of simvastatin on gentamicin-induced $\mathrm{HC}$ damage was dose dependent in the middle and basal turn (Figure 3).

\section{Mevalonate does not effect gentamicin-induced HC damage in vitro and has no toxic effect on hair cells in vitro itself}

To exclude a toxic effect of mevalonate, the OCs were cultured with the dosages used in this study $(100 \mu \mathrm{M})$ for 72 hours. The number of HCs was compared between cultured $\mathrm{OC}$ in presence and absence of mevalonate. Because no difference was found, a toxic effect of mevalonate was excluded. Untreated control OCs and those treated with mevalonate alone showed three orderly rows of OHCs and a single row of IHCs (Figure 2). Treatment with gentamicin and mevalonate showed no statistically significant difference in OHC survival compared to treatment with gentamicin only in all cochlear turns (Figure 3).

\section{Mevalonate reverses the protective effect of simvastatin on gentamicin-induced $\mathrm{HC}$ damage in vitro}

Treatment with simvastatin $10 \mu \mathrm{M}$ in addition to gentamicin showed significantly less $\mathrm{OHC}$ loss in all cochlear turns than groups treated with gentamicin only or with simvastain $10 \mu \mathrm{M}$ and mevalonate $100 \mu \mathrm{M}$ in addition

Table 1 Primer sequences used for HMG-CoA reductase and $\beta$-actin

\begin{tabular}{|c|c|c|c|c|c|}
\hline Gene & Primer name & Sequence $5^{\prime} \rightarrow 3^{\prime}$ & Annealing temperature & Exons & Product length \\
\hline \multirow[t]{2}{*}{ HMG-CoA reductase } & Forward & TGTTCAAGGGGCGTGCAAAGACAA & 63 & 17 & 202 bp \\
\hline & Reverse & TCAAGCTGCCTTCTTGGTGCATGT & & 18 & \\
\hline \multirow[t]{2}{*}{$\beta$-actin } & Forward & ACGGTCAGGTCATCACTATCGGCA & 58 & 3 & $208 \mathrm{bp}$ \\
\hline & Reverse & ATCCTGTCAGCAATGCCTGGGT & & 4 & \\
\hline
\end{tabular}




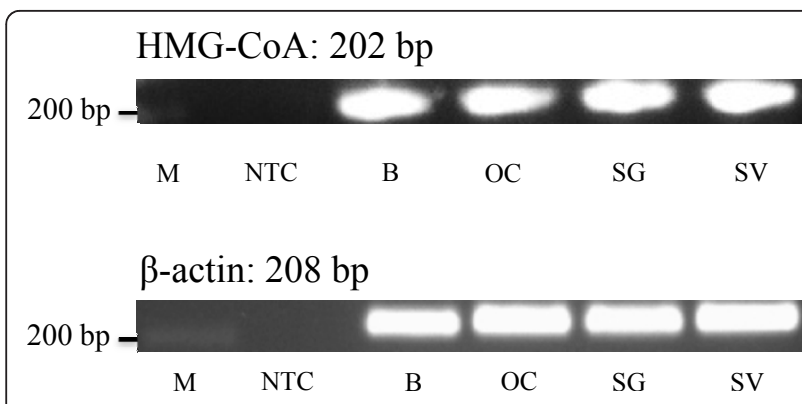

Figure 1 Detection of HMG-CoA reductase in the cochlea of 5day-old Wistar rats. Total RNA of the organ of Corti (OC), the spiral ganglion (SG) and the stria vascularis (SV) was reversed transcribed into CDNA and amplified by PCR. Total brain (B) RNA served as a positive control. Omission of CDNA in the PCR mixture served as no template control (NTC). The DNA ladder (M) is indicated with its lengths. $\beta$-actin was used to control cDNA synthesis.

to gentamicin (Figure 3). The protective effect of simvastatin was reversed by the addition of mevalonate, a downstream metabolite. This bypasses the effect of simvastatin on the upstream enzyme, 3-hydroxy-3-methylglutaryl-coenzyme A, demonstrating the mechanism of protection.

\section{Simvastatin increases Akt phosphorylation in vitro}

Western blotting revealed specific activation of Akt in OC treated with simvastatin in vitro (Figure 4 ). Blots using anti-pAkt revealed a strong increase in activated Akt, after a 1 hour exposure to $10 \mu \mathrm{M}$ simvastatin. p-Akt has been referenced to total Akt in the control and simvastatin treated group (Figure 4).

\section{Discussion}

At present, little is known about the effects of statins on the inner ear. It has been hypothesized that statins might be useful as a treatment for sudden sensorineural hearing loss due to their metabolic and hemodynamic effects [26]. Syka et al. demonstrated that atrovastin had a positive effect on the deterioration of inner ear function with age in mice by analysing distortion product otoacoustic emissions (DPOAE). Treated mice showed decreased expression of intracellular and vascular adhesion molecules in the aortic wall and the authors suggest that reduced endothelial inflammatory effects may contribute to better $\mathrm{OHC}$ survival by influencing blood supply to the inner ear [25]. While Syka et al. attribute the positive effect of statins on inner ear function on hemodynamic effects, other reports suggest that statins act through their metabolic effects. It has been reported that simvastatin may prevent hearing loss and inner ear damage in apolipoprotein $\mathrm{E}$ gene knockout mice fed a high-fat diet, by reducing atherosclerotic lesions and levels of glucose, cholesterol, low density lipoproteins, and triglyceride [24]. Therefore it was suggested that statins might be used to treat hearing loss associated with hyperlipedemia.

Toxic effects of simvastatin on the inner ear have also been reported. Park et al. found that simvastatin treatment induced morphological alterations and apoptosis in murine cochlear neuronal cells [29]. Chiu et al. reported that simvastatin was toxic to lateral line $\mathrm{HCs}$ in the zebrafish [28]. Given these conflicting data, we evaluated the effects of simvastatin on cochlear HCs in vitro. We demonstrate that HMG-CoA reductase mRNA is expressed in the cochlea. We excluded a toxic effect of simvastatin exposure on auditory HCs. Treatment with simvastatin in addition to gentamicin led to significant decrease in $\mathrm{HC}$ loss compared with the gentamicin group. Although simvastatin enhanced $\mathrm{HC}$ survival, it did not provide complete protection against gentamicin-induced HC loss. Western blotting reveals that simvastatin increased Akt phosphorylation in the $\mathrm{OC}$ in vitro, indicating that the PI3K/Akt pathway may contribute to the protective effects achieved. It is significant that the protective effect of simvastatin was reversed by addition of mevalonate, since this finding demonstrates the specificity of protection to the metabolic pathway that is regulated by statins.

It should be noted that in our experiments cochlear explants were harvested from postnatal day 3-5 animals since only newborn animals can be used for extended culture of inner ear HCs. Adult HCs do not survive in culture. In a large number of studies, aminoglycosides have been utilized as inducers of $\mathrm{HC}$ death and the immature cochlea is an established in vitro model. However, younger animals are more sensitive to ototoxins $[3,4,7]$ and therefore our results must generalize to adults with caution. It should be noted that for the RT-PCR and Western blotting experiments we used Wistar rat pups, whereas for the in vitro experiment transgenic mouse pups in which expression of green fluorescent protein (GFP) is driven by an auditory $\mathrm{HC}$ specific promoter were used. The rationale for this is that the larger cochlea of the rat allows more tissue to be harvested and fewer animals needed to be sacrificed for the experiments. The transgenic mouse pups were chosen for the in vitro experiments in order to easily visualize the GFP-positive $\mathrm{HCs}$, and to monitor $\mathrm{HC}$ loss while the cells were alive.

The possibility that simvastatin might interact physically with gentamicin must also be considered. Although we have no direct evidence excluding physical interaction, the fact that the protective effect of simvastatin on gentamicin-induced $\mathrm{HC}$ loss was reversed by adding mevalonate argues against it.

How can the protective effect of simvastatin in gentamicin-induced $\mathrm{HC}$ loss be explained? To date there are no reports of simvastatin-induced intracellular events on $\mathrm{HCs}$ available. Certain evidence suggests that the reduction of cholesterol cannot entirely account for statins' 


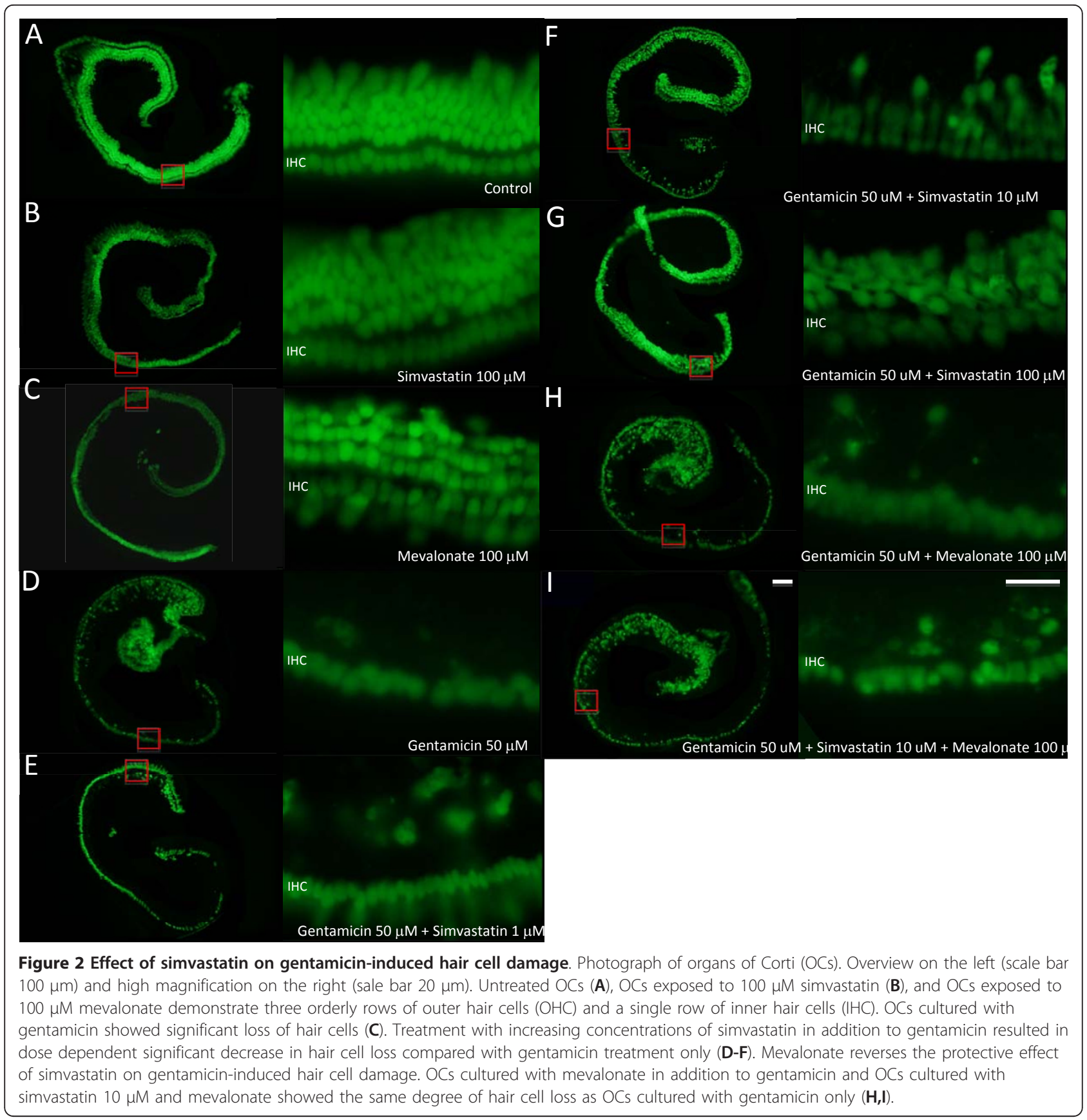

neuroprotective effects and it has been demonstrated that short-term statin treatment does not alter cholesterol level in the brain. This indicates that statins have another mechanism of action, possibly through the other products of the mevalonate pathway that play a role in cellular signalling [30,31]. This is not surprising since mevalonate is not only essential for the biosynthesis of cholesterol, but also for other products, such as Coenzyme Q10 (Q10) and isoprenylated proteins, which are essential in several cell processes [22,32].
Several in vitro and in vivo studies provided evidence that statins activate the PKB/Akt pathway $[21,22]$. Work done in the retina has shown that simvastatin increases Akt phosphorylation in vivo, indicating that the PI3K/ Akt pathway contributes to the central nervous system protective effects achieved [26]. In a previous study, we demonstrated that PI3K mediates $\mathrm{HC}$ survival and opposes gentamicin toxicity in neonatal rat OC [9]. Therefore, activation of Akt by simvastatin as demonstrated here is one explanation for the protective effects 


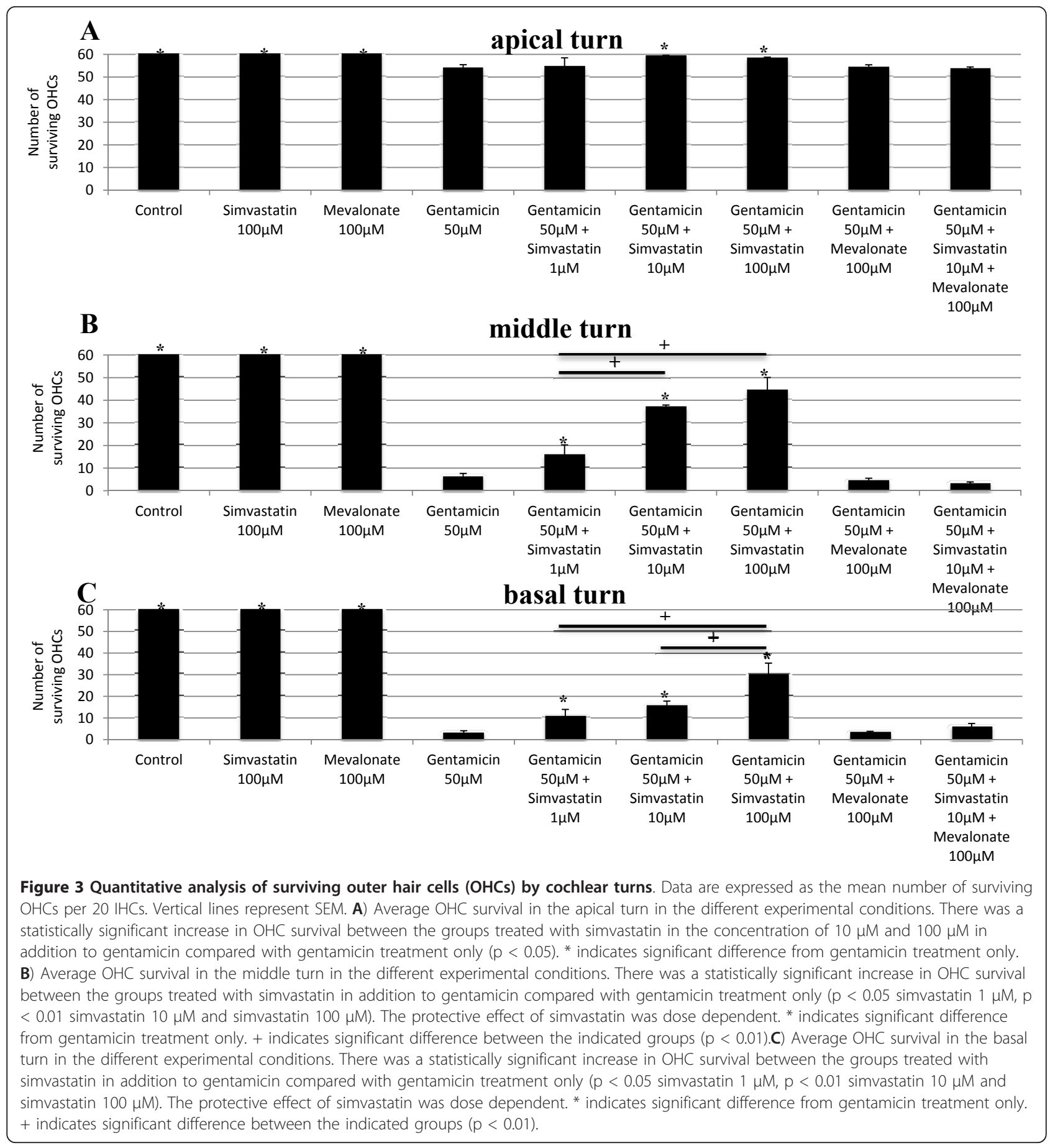

of the drug on gentamicin-induced HC loss. A study on mammalian endothelial cells demonstrated that simvastatin activates Akt in these cells, while treatment with mevalonate blocked this activation of Akt [22]. This finding directly links HMGCoA reductase -mevalonate metabolism to Akt activation. Our study is the first demonstration, to our knowledge, that this pathway is involved in Akt activation in the inner ear.
A second potential mechanism through which statins can affect cells is by blocking the isoprenylation of small $\mathrm{G}$ proteins, such as Ras and Rho/Rac/Cdc42. It has been shown that statins downregulate the activity of small $\mathrm{G}$ proteins in cardiomyocytes in culture and in vivo [33]. In previous studies, we showed that inhibition of the small GTPases Rho/Rac/Cdc42 or specific blocking of Ras provided potent protection against gentamicin- 


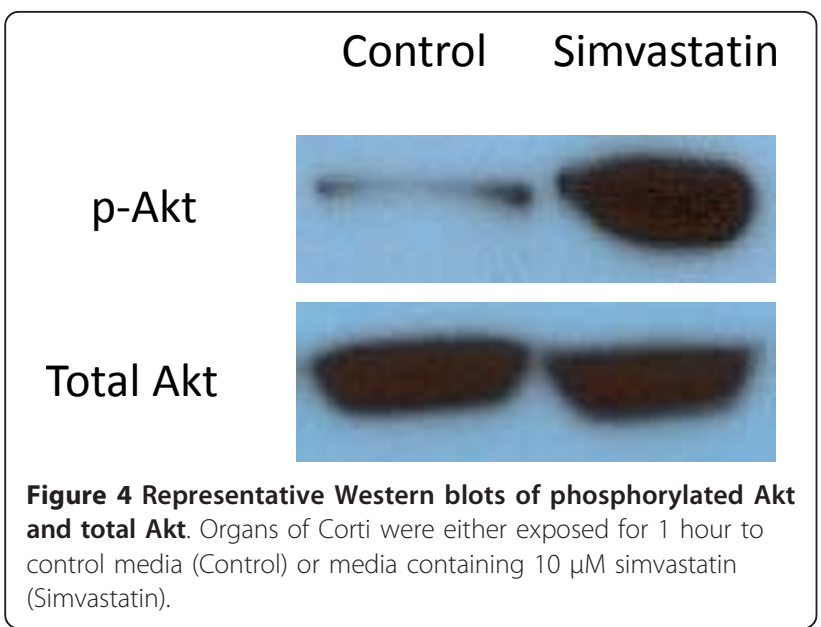

induced auditory $\mathrm{HC}$ loss $[5,6]$. Since mevalonate alone does not affect $\mathrm{HC}$ death, this implies that sufficient prenylated Ras is normally present in $\mathrm{HCs}$, and that additional mevalonate does not enhance damage signaling. However, we did not evaluate the role of small G proteins in this study. Our conclusions on the protective effect of simvastatin in gentamicin-induced $\mathrm{HC}$ loss are summarized in Figure 5.

As mentioned above, simvastatin has been shown to have a toxic effect on fish lateral line HCs and cochlear neurons $[28,29]$. The concentration of simvastatin used in this study is in the same range used on cochlear neurons [29]. Although this prior work did not address mammalian HCs, potential toxic effects need to be considered. Mevalonate is essential for the production of coenzyme Q10 and statins lead to a dose-dependent reduction in Q10 [34]. Q10 is an important mitochondrial antioxidant that helps bypass existing mitochondrial respiratory chain defects. Mitochondrial predispositions and dysfunction are thought to play a major role in adverse effects of statins, and it has been demonstrated that water-soluble Q10 promotes OHC survival in a guinea pig model of noise induced hearing loss $[35,36]$. We hypothesize that zebrafish HCs and mouse cochlear neurons might be more vulnerable to Q10 reduction by simvastatin than mouse cochlear HCs. While this hypothesis is perhaps too complex to be attractive without additional supporting data, it is at least consistent with our observations and with the current literature.

\section{Conclusion}

Our results demonstrate a partial protection of OHCs in the $\mathrm{OC}$ against gentamicin ototoxicity in vitro. This neuroprotective effect of statins on mammalian auditory HCs is mediated by reduced 3-hydroxy-3-methylglutaryl-coenzyme A reductase metabolism and Akt activation.

\section{Methods}

\section{Animal procedures}

The animal procedures for the RT-PCR were carried out in Basel, Switzerland according to an approved animal research protocol (Kantonales Veterinäramt, Basel, Switzerland) in accordance with the European Communities Council Directive of 24 November 1986 (86/609/EEC). All other animal procedures were carried out in San Diego, CA USA. The local animal subject committee of the VA San Diego Healthcare System approved the animal procedures in accordance with the guidelines laid down by the National Institute of Health regarding the care and use of animals for experimental procedures.

\section{Tissue extraction}

For RT-PCR and western blotting tissue was extracted from 5-day-old Wistar rat pups (Harlan, Indianapolis, IN, USA). For all other experiments 3-day-old transgenic mice pups in which expression GFP is driven by an auditory HC specific Brn-3.1 promoter were used [37]. The animals were decapitated, and cochlear microdissections were performed under a light microscope to isolate the OC, the SG, and the SV [38]. Brain tissue was removed from the same animals as a positive control for the RTPCR. During the microdissection, the different tissues were maintained in ice-cold PBS.

\section{Tissue culture}

For experiments in which cultures of OCs were needed, OCs were first incubated in culture medium [Dulbecco's Modified Eagle Medium supplemented with 10\% FCS, $25 \mathrm{mM}$ HEPES and $30 \mathrm{U} / \mathrm{ml}$ penicillin (Invitrogen, Carlsbad, CA, USA) at $37^{\circ} \mathrm{C}$ in $5 \% \mathrm{CO}_{2}$ ] and left for 24 hours at $37^{\circ} \mathrm{C}$ in $5 \% \mathrm{CO}_{2}$ for recovery. After that period, the OCs were transferred into a new solution and incubated for 48 hours at $37^{\circ} \mathrm{C}$ in $5 \% \mathrm{CO}_{2}$. To induce $\mathrm{HC}$ damage, OCs were cultured with $50 \mu \mathrm{M}$ gentamicin (Sigma-Aldrich, St. Louis, MO, USA) in cell culture medium for 48 hours. OCs were pretreated for 24 hours with increasing amounts of simvastatin (Sigma-Aldrich) at the final concentration of $1 \mu \mathrm{M}, 10 \mu \mathrm{M}$ or $100 \mu \mathrm{M}$ in the cell culture medium, mevalonate $100 \mu \mathrm{M}$ in cell culture medium and with simvastatin $10 \mu \mathrm{M}$ in combination with mevalonate $100 \mu \mathrm{M}$ in cell culture medium during the 24 hour recovery period after dissection. Before use simvastatin was converted into the active acid following the protocol of Bogman et al. [39]. Stock solutions of $10 \mu \mathrm{M}$ simvastatin in DSMO were stored at $-20^{\circ} \mathrm{C}$. After this pretreatment, OCs were exposed either to gentamicin and simvastatin for 48 hours or to gentamicin in combination with simvastatin and mevalonate for 48 hours. Other OCs were either held in culture medium alone (control), treated with simvastatin at a final concentration of $100 \mu \mathrm{M}$ or with mevalonate at a final concentration of $100 \mu \mathrm{M}$. 


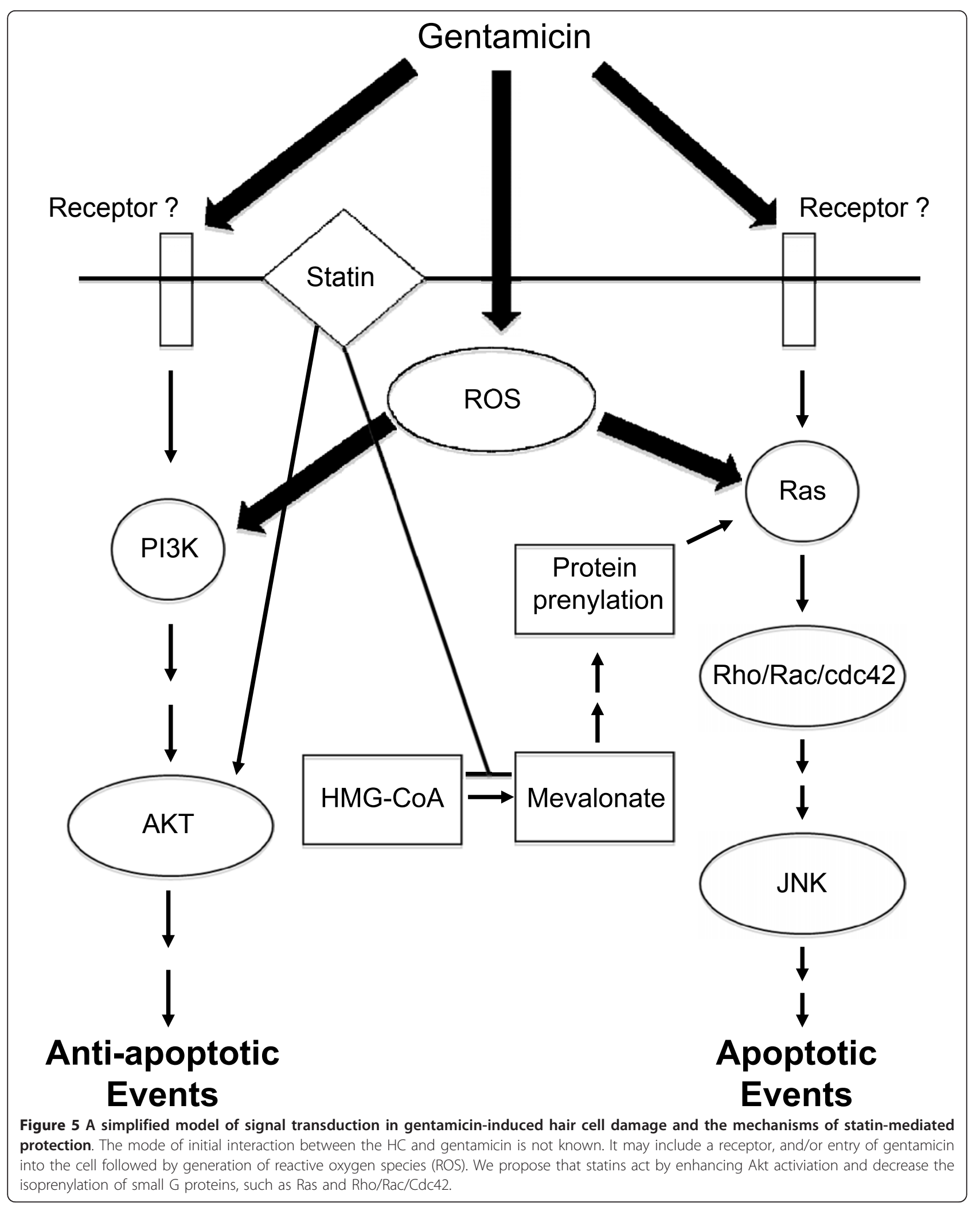




\section{RNA extraction}

For PCR, 20 OCs, SGs, SVs and 20-40 mg brain of 5day-old WS rat pups were separately placed in RNAlater (Qiagen, Hombrechtikon, Switzerland). RNA isolation of brain and inner ear components were performed using the RNAeasy Minikit (Qiagen) including DNase treatment according to the supplier's instructions. To homogenize the tissues, we used homogenizer Ultra-Turrax T8 (IKA-Werke, Staufen, Germany). The quantity and quality of the isolated RNA was determined with NanoDrop ND 1000 (NanoDrop Technologies, Delaware, USA). The $260 / 280 \mathrm{~nm}$ ratio of all our samples was between 1.8 and 2.1 .

\section{Primer design}

Gene sequences from HMG-CoA reductase (NM_013134.2) and $\beta$-actin (NM_031144.2) were accessed from GenBank. Primers for RT-PCR were designed using Primer-Blast software available at the NCBI (National Center for Biotechnology Information). Our criteria for primer design included $T_{\mathrm{m}}$ values between $58^{\circ} \mathrm{C}$ and $60^{\circ} \mathrm{C}$, a minimum length of $20 \mathrm{nt}$, a product size of 100-500 bp, with an absence of long G-C stretches. Primers were designed to cross at least one exon junction for the specific amplification of cDNA and to avoid amplification of genomic DNA. The details of primers employed along with the annealing temperatures and product sizes are provided in Table 1.

\section{Reverse Transcriptase-Polymerase Chain Reaction}

Total RNA $(1 \mu \mathrm{g})$ was reverse transcribed into cDNA with the first-strand cDNA synthesis kit (Roche Applied Biosciences, Rotkreuz, Switzerland) according to the supplier's instructions. PCR was performed using the PCR Master Mix (Roche Applied Biosciences) with primers specific for HMG-CoA reductase. $\beta$-actin primers were used as a positive control for cDNA synthesis. The primer sets are described in Table 1 . PCR reactions were run in the Eppendorf Mastercycler (Eppendorf, Hamburg, Germany) under the following conditions. For HMG-CoA reductase, we started with an initial denaturation of $94^{\circ} \mathrm{C}$ for $3 \mathrm{~min}$ utes and followed by 30 cycles. Each cycle consisted of denaturation at $94^{\circ} \mathrm{C}$ for 30 seconds, annealing at $63^{\circ} \mathrm{C}$ for 30 seconds and extension at $72^{\circ} \mathrm{C}$ for 30 seconds, with a final extension step at $72^{\circ} \mathrm{C}$ for 5 minutes. For $\beta$-actin, we started with an initial denaturation of $94^{\circ} \mathrm{C}$ for 3 minutes and followed by 30 cycles. Each cycle consisted of denaturation at $94^{\circ} \mathrm{C}$ for 30 seconds, annealing at $58^{\circ} \mathrm{C}$ for 45 seconds and extension at $72^{\circ} \mathrm{C}$ for 30 seconds, with a final extension step at $72^{\circ} \mathrm{C}$ for 1 minute. The PCR products were stained with SybrGreen I (Molecular Probes, Oregon, USA), separated by electrophoresis on a $2 \%$ agarose gel and visualized under UV light. Omission of cDNA in the PCR mixture served as negative control.

\section{Hair cell count}

OCs were fixed in $4 \%$ paraformaldehyde. After fixation, the OCs were visualized and photographed using a fluorescence microscope (Olympus FSX100). Quantitative analysis was obtained by evaluating $60 \mathrm{OHCs}$ associated with 20 IHCs in a given microscope field. Explants were analyzed separately for the apical, middle and basal turn. For each turn, two random microscope fields were counted and averaged. These values were averaged across the six replications of each experiment. Since there was almost no damage to the IHCs $(<5 \%)$, only the OHCs were counted and used to analyze $\mathrm{HC}$ survival.

Results obtained in the $\mathrm{HC}$ counting were analyzed by using analysis of variance (ANOVA) followed by the least significant difference (LSD) post-hoc test (Stat View 5.0). Differences associated with P-values of less than 0.05 were considered to be statistically significant. All data are presented as mean $\pm \mathrm{SD}$.

\section{Assessment of Signaling Protein Activation}

To assess the activation of the PIK3/Akt signaling pathway, per condition 6 intact OCs from 5-day-old Wistar rat pups (Harlan) were harvested and placed in cell culture media for 24 hours as described above. They were then placed in cell culture media, with or without 10 $\mu \mathrm{g} / \mathrm{ml}$ simvastatin for 1 hour. Explants were collected from media, and lysed with $100 \mu \mathrm{l}$ T-Per Tissue Protein Extraction Reagent (Thermo Scientific, Rockford, IL, USA) in $1 \mathrm{X}$ phosphatase/proteases inhibitors (Roche, Indianapolis, IN, USA) and sonicated for $10 \mathrm{~min}$ to shear chromosomal DNA. Samples where centrifuge at 10,000G for 10 minutes to separate cytosolic part from membranous components. Equal quantities of these lysates were separated by Bis-Tris Mini Gels 4-12\% gels, and electrotransferred to polyvinylidene difluoride membranes (Bio-Rad, Hercules, CA, USA). The membranes were blocked with $5.5 \%$ nonfat dried milk in TBSTween [50 mM Tris-HCL (pH 7.4), $150 \mathrm{mM} \mathrm{NaCl}$, $0.05 \%$ Tween 20] for $60 \mathrm{~min}$ at room temperature. Blots were incubated with primary antibodies in blocking buffer overnight at $4^{\circ} \mathrm{C}$ and then incubated with horseradish peroxidase-linked secondary antibodies (Jackson Immuno, West Grove, PA, USA) followed by chemiluminescent detection (GE Healthcare, Piscataway, NJ, USA). Blots were evaluated with antibodies against the phosphorylated forms of Akt, and total Akt (both Cell Signaling Technology, Beverly, MA, USA) on the same membrane. Western blotting was replicated three times with independent biological replicas.

Acknowledgements and Funding

Supported by grants by the Novartis Stiftung medizinisch-biologische Forschung, Basel, Switzerland and the Schwerhörigenverein

Nordwestschweiz (DB), by the Research Service of the VA and NIH/NIDCD 
grant DC000139 (AFR), and by Swiss National Science Foundation grant PBBSP3-13097 (YB).

\section{Author details}

'Department of Biomedicine, University Hospital Basel, Hebelstrasse 20, 4031 Basel, Switzerland. ${ }^{2}$ Clinic of Otolaryngology, Head and Neck Surgery, University Hospital Basel, Petersgraben 4, 4031 Basel, Switzerland. ${ }^{3}$ San Diego VA Medical Center, 3350 La Jolla Village Drive, La Jolla, CA 92037, USA. ${ }^{4}$ Surgery/Otolaryngology, UCSD School of Medicine, 9500 Gilman Drive MC0666, La Jolla, CA 92093-0666, USA. ${ }^{5}$ Neurosciences Departments, UCSD School of Medicine, 9500 Gilman Drive MC0666, La Jolla, CA 92093-0666, USA

\section{Authors' contributions}

YB participated in the design of the study, carried out the RT-PCR, hair cell count and drafted the manuscript. CS, AL, KP, MS and VR participated in the tissue culture for the hair cell count and RT-PCR. SL was involved in the primer design for the RT-PCR and participated in the design of the study. EC carried out the assessment of signaling protein activation by Western blotting. AFR and DB conceived the study, and participated in its design and coordinated and helped to draft the manuscript. All authors read and approved the final manuscript.

Received: 19 August 2011 Accepted: 14 November 2011

Published: 14 November 2011

\section{References}

1. Matsui JI, Cotanche DA: Sensory hair cell death and regeneration: two halves of the same equation. Curr Opin. Otolaryngol. Head Neck Surg 2004, 12:418-425.

2. Cheng AG, Cunningham LL, Rubel EW: Mechanisms of hair cell death and protection. Curr Opin Otolaryngol Head Neck Surg 2005, 13:343-348.

3. Lautermann J, Dehne N, Jahnke K: Aminoglycoside- and cisplatinototoxicity: from basic science to clinics. Laryngorhinootologie 2004, 83:317-323.

4. Rybak LP, Whitworth CA: Ototoxicity: therapeutic opportunities. Drug Discov Today 2005, 10:1313-1321.

5. Battaglia A, Pak K, Brors D, Bodmer D, Frangos J, Ryan A: Involvement of ras activation in toxic hair cell damage of the mammalian cochlea. Neuroscience 2003, 122:1025-1035.

6. Bodmer D, Brors D, Pak K, Gloddek B, Ryan AF: Rescue of auditory hair cells from aminoglycoside toxicity by Clostridium difficile toxin $B$, an inhibitor of the small GTPases Rho/Rac/Cdc42. Hear Res 2002, 172::81-86

7. Pirvola U, Xing-Qun L, Virkkala J, Saarma M, Murakata C, Camoratto AM, Walton KM, Ylikoski J: Rescue of hearing, auditory hair cells, and neurons by CEP-1347/KT7515, an inhibitor of c-Jun N-terminal kinase activation. $J$ Neurosci 2000, 20:43-50.

8. Bodmer D, Brors D, Bodmer M, Ryan AF: Rescue of auditory hair cells from ototoxicity by CEP-11004, an inhibitor of the JNK signalling pathway. Laryngorhinootologie 2002, 81:853-856

9. Chung WH, Pak K, Lin B, Webster N, Ryan AF: A PI3K pathway mediates hair cell survival an opposes gentamicin toxiciy in neonatal rat organ of Corti. J Assoc Res Otolaryngol 2006, 7:372-382.

10. Huang T, Chen AG, Stupak H, Liu W, Kim A, Staecker H, Lefebvre PP, Malgrange B, Kopke R, Moonen G, Van De Water TR: Oxidative stressinduced apoptosis of cochlear sensory cells: otoprotective strategies. Int J Dev Neurosci 2000, 18:259-270.

11. Okuda T, Sugahara K, Takemoto T, Shimogori H, Yamashita $H$ : Inhibition of caspases alleviates gentamicin-induced cochlear damage in guinea pigs. Auris Nasus Larynx 2005, 32:33-37.

12. Castilla GL, Del Carmen Fernandez MM, Lopez Chozas JM, Jimene H: Statins in stroke prevention: what an internist should know. Eur J Intern Med 2008, 19:8-14

13. Nassief A, Marsh JD: Statin therapy for stroke prevention. Stroke 2008 , 39:1042-1048

14. Aktas O, Waiczies S, Smorodchenko A, Dorr J, Seeger B, Prozorovski T, Sallach S, Endres M, Brocke S, Nitsch R, Zipp F: A treatment of relapsing paralysis in experimental encephalomyelitis by targeting Th1 cells through atorvastatin. J Exp Med 2003, 197:725-733.

15. Floris S, Blezer EL, Schreibelt G, Döpp E, van der Pol SM, SchadeeEestermans IL, Nicolay K, Dijkstra CC, de Vries HE: Blood-brain barrier permeability and monocyte infiltration in experimental allergic encephalomyelitis: a quantitative MRI study. Brain 2004, 127:616-627.

16. Greenwood J, Walters CE, Pryce G, Kanuga N, Beraud E, Baker D, Adamson P: Lovastatin inhibits brain endothelial cell Rho-mediated lymphocyte migration and attenuates experimental autoimmune encephalomyelitis. FASEB J 2003, 17:905-907.

17. Paintlia AS, Paintlia MK, Singh AK, Stanislaus R, Gilg AG, Barbosa E, Singh I: Regulation of gene expression associated with acute experimental autoimmune encephalomyelitis by Lovastatin. J Neurosci Res 2004, 77:63-81.

18. Berger C, Xia F, Maurer MH, Schwab S: Neuroprotection by pravastatin in acute ischemic stroke in rats. Brain Res Rev 2008, 58:48-56.

19. Chen J, Zhang C, Jiang H, Zhang L, Robin A, Katakowski M, Lu M, Chopp M: Atorvastatin induction of VEGF and BDNF promotes brain plasticity after stroke in mice. J Cereb Blood Flow Metab 2005, 25:281-290.

20. Sironi L, Cimino M, Guerrini U, Calvio AM, Lodetti B, Asdente M, Balduini W, Paoletti $R$, Tremoli E: Treatment with statins after induction of focal ischemia in rats reduces the extent of brain damage. Arterioscler Thromb Vasc Biol 2003, 23:322-327.

21. Dimmeler S, Aicher A, Vasa M, Mildner-Rihm C, Adler K, Tiemann M, Rütten $\mathrm{H}$, Fichtlscherer $\mathrm{S}$, Martin $\mathrm{H}$, Zeiher AM: HMG-CoA reductase inhibitors (statins) increase endothelial progenitor cells via the PI 3kinase/Akt pathway. J Clin Invest 2001, 108:391-497.

22. Kureishi Y, Luo Z, Shiojima I, Bialik A, Fulton D, Lefer DJ, Sessa WC, Walsh E: The HMG-CoA reductase inhibitor simvastatin activates the protein kinase Akt and promotes angiogenesis in normocholesterolemic animals. Nat Med 2000, 6:1004-1010.

23. Kretz A, Schmeer C, Tausch S, Isenmann S: Simvastatin promotes heat shock protein 27 expression and Akt activation in the rat retina an protects axotomized retinal ganglion cells in vivo. Neurobiol Dis 2006, 21:421-430.

24. Cai Q, Du X, Zhou B, Cai C, Kermany MH, Zhang C, Yoo T: Effects of simvastatin on plasma lipoproteins and hearing loss in apolipoprotein $E$ gene-deficient mice. ORL J Otorhinolaryngol Relat Spec 2009, 71:244-250.

25. Syka J, Ouda L, Nachtigal P, Solichova D, Semecky V: Atrovastin slows down the deterioration of inner ear function with age in mice. Neurosci Lett 2007, 411:112-116.

26. Borghi C, Modugno G, Pirodda A: Possible role of HMG-CoA reductase inhibiors for the treament of sudden sensorineural hearing loss (SSHL). Med Hypotheses 2002, 58:399-402.

27. Olzowy B, Canis M, John-Martin Hempel, Brigit Mazurek, Suckfüll M: Effect of atrovastin on progression of sensorineural hearing loss and tinnitus in the elderly: results of a prospective, randomized, double-blind clinical trial. Otol Neurootol 2007, 28:455-458.

28. Chiu LL, Cunningham LL, Raible DW, Rubel EW, Ou HC: Using the zebrafish lateral line to screen for ototoxicity. J Assoc Res Otolaryngol 2008, 9:178-190.

29. Park DS, So HS, Lee JH, Park H, Lee YJ, Cho JH, Yoon KH, Park C, Yun K, Park R: Simvastatin treatment induces morphology alterations and apoptosis in murine cochlear neuronal cells. Acta Otolaryngol 2009, 129:166-74.

30. Liao JK, Lauf U: Pleiotropic effects of statins. Annu Rev Pharmacol Toxicol 2005, 45:89-118.

31. Wierzbicki AS, Poston R, Ferro A: The lipid and non-lipid effects of statins. Pharmacol Ther 2003, 99:95-112.

32. Buhaescu I, Izzedine $\mathrm{H}$ : Mevalonate pathway: a review of clinical and therapeutical implications. Clin Biochem 2007, 40:575-584.

33. Laufs U, Kilter H, Konkol C, Wassmann S, Böhm M, Nickening G: Impact of HMG CoA reductase inhibitor on small GTPases in the heart. Cardiovasc Res 2002, 53:911-920

34. Mortensen SA, Leth A, Agner E, Rohde M: Dose-related decrease of serum coenzyme Q10 during treatment with HMG-CoA reductase inhibitors. Mol Aspects Med 1997, 18:137-144.

35. Golomb BA, Evans MA: Statins adverse effects: a review of the literature and evidence for a mitochondrial mechanism. Am J Cardiovasc Drugs 2008, 8:373-418

36. Fetoni AR, Piacentini R, Fiorita A, Paludetti G, Troiani D: Water-soluble Coenzyme Q10 formulation (Q-ter) promotes outer hair cell survival in guinea pig model of noise induced hearing loss (NIHL). Brain Res 2009, 1257:108-116. 
37. Keithley EM, Wang X, Barkdull GC: Tumor necrosis factor alpha can induce recruitment of inflammatory cells to the cochlea. Otol Neurootol 2008, 29:854-859.

38. Sobkowicz HM, Loftus JM, Slapnick SM: Tissue culture of the organ of Corti. Acta Otolaryngol Suppl 1993, 502:3-36.

39. Bogman K, Peyer AK, Török M, Kusters E, Drewe J: HMG-CoA reductase inhibitors and P-glycoprotein modulation. Br J Pharmacol 2001, 132:1183-1192

doi:10.1186/1471-2202-12-114

Cite this article as: Brand et al: Simvastatin protects auditory hair cells from gentamicin-induced toxicity and activates Akt signaling in vitro.

BMC Neuroscience 2011 12:114.

Submit your next manuscript to BioMed Central and take full advantage of:

- Convenient online submission

- Thorough peer review

- No space constraints or color figure charges

- Immediate publication on acceptance

- Inclusion in PubMed, CAS, Scopus and Google Scholar

- Research which is freely available for redistribution

Submit your manuscript at www.biomedcentral.com/submit 